\title{
Combined use of repeated active shots and ambient noise to detect temporal changes in seismic velocity: application to Sakurajima volcano, Japan
}

\author{
Takashi Hirose* ${ }^{*}$, Hisashi Nakahara and Takeshi Nishimura
}

\begin{abstract}
Coda-wave interferometry is a technique to detect small seismic velocity changes using phase changes in similar waveforms from repeating natural or artificial sources. Seismic interferometry is another technique for detecting seismic velocity changes from cross-correlation functions of ambient seismic noise. We simultaneously use these two techniques to clarify seismic velocity changes at Sakurajima volcano, one of the most active volcanoes in Japan, examining the two methods. We apply coda-wave interferometry to the records of repeated active seismic experiments conducted once a year from 2011 to 2014, and seismic interferometry to the ambient seismic noise data. We directly compare seismic velocity changes from these two techniques. In coda-wave interferometry analyses, we detect significant seismic velocity increases between 2011 and 2013, and seismic velocity decreases between 2013 and 2014 at the northern and eastern flanks of the volcano. The absolute values are at a maximum $0.47 \pm 0.06 \%$ for $2-4 \mathrm{~Hz}, 0.24 \pm 0.03 \%$ for $4-8 \mathrm{~Hz}$, and $0.15 \pm 0.03 \%$ for $8-16 \mathrm{~Hz}$, respectively. In seismic interferometry analyses, vertical-vertical cross-correlations in $1-2,2-4$, and $4-8 \mathrm{~Hz}$ bands indicate seismic velocity increases and decreases during 3 years of 2012-2014 with the maximum amplitudes of velocity change of $\pm 0.3 \%$ for $1-2 \mathrm{~Hz}, \pm 0.4 \%$ for $2-4 \mathrm{~Hz}$, and $\pm 0.2 \%$ for $4-8 \mathrm{~Hz}$, respectively. Relative velocity changes indicate the almost annual change. These periodical changes are well matched with volcano deformation detected by GNSS receivers deployed around the volcano. We compare the results from coda-wave interferometry with those from seismic interferometry on the shot days and find that most of them are consistent. This study illustrates that the combined use of coda-wave interferometry and seismic interferometry is useful to obtain accurate and continuous measurements of seismic velocity changes.
\end{abstract}

Keywords: Coda-wave interferometry, Seismic interferometry, Seismic velocity change, Active seismic experiment, Ambient noise, Sakurajima volcano

\section{Background}

Temporal changes in seismic velocity associated with large earthquakes or volcanic activities have been detected from analyses of coda-wave interferometry or seismic interferometry. These interferometric techniques are now widely used to monitor temporal changes in structure. Coda-wave interferometry is a technique to

\footnotetext{
*Correspondence: hirose@zisin.gp.tohoku.ac.jp

Department of Geophysics, Graduate School of Science, Tohoku

University, 6-3, Aramaki Aza-Aoba, Aoba-ku, Sendai, Miyagi 980-8578, Japan
}

Springer Open

(c) The Author(s) 2017. This article is distributed under the terms of the Creative Commons Attribution 4.0 International License (http://creativecommons.org/licenses/by/4.0/), which permits unrestricted use, distribution, and reproduction in any medium, provided you give appropriate credit to the original author(s) and the source, provide a link to the Creative Commons license, and indicate if changes were made.

detect slight changes in medium properties by measuring phase changes or waveform changes in coda waves from repetitive similar sources (e.g., Poupinet et al. 1984; Snieder et al. 2002; Snieder 2006). Poupinet et al. (1984) first applied coda-wave interferometry to an earthquake doublet consisting of two micro-earthquakes that occurred 14 months before and 7 months after the M5.9 Coyote Lake, California, earthquake, and detected seismic velocity decrease of $0.2 \%$. Nishimura et al. (2000, 2005) analyzed records of repeated active seismic experiments conducted at Iwate volcano, Japan, from 1998 to 2003, and detected seismic velocity decrease of about 
1\%. These two studies interpreted that these velocity decreases were caused by static stress change in shallow structures close to M5.9 or M6.1 earthquakes and/or volcanic pressure sources. Cannata (2012) applied codawave interferometry to repeating volcano-tectonic earthquakes that occurred with about 3-h interval at Mt. Etna and obtained detailed temporal seismic velocity changes in the volcanic edifice. However, such a high time resolution is rare in general, because the time intervals of repeating earthquakes or repeated active seismic experiments are usually long in time.

On the other hand, seismic interferometry, which is a technique to estimate relative seismic velocity changes using cross-correlation functions of ambient seismic noise (e.g., Shapiro and Campillo 2004; Curtis et al. 2006), enables us to continuously monitor seismic velocity changes. Brenguier et al. (2008) determined seismic velocity changes at Piton de la Fournaise volcano every 10 days. They interpreted the observed seismic velocity decrease of about $0.1 \%$ preceding eruptions at the volcano by dilatation of the edifice due to pressure increase in the magma. Takagi et al. (2012) detected a coseismic decrease in Rayleigh wave velocity of $0.1-0.5 \%$ related to the occurrence of the 2008 Iwate-Miyagi Nairiku earthquake, NE Japan (M7.2). Since ambient noises are available everywhere, seismic interferometry has been applied at many fields for continuous monitoring (e.g., SensSchönfelder and Wegler 2011). However, ambient noise source distribution may affect the quality of retrieved Green's functions and accordingly relative seismic velocity changes. For example, Stehly et al. (2006) demonstrated that noise sources show a clear seasonal variation; the noise sources in $0.05-0.1 \mathrm{~Hz}$ are located in the northern Atlantic and the Pacific during the winter in the northern hemisphere, while in the Indian Ocean and in the Southern Pacific during the summer in the northern hemisphere.

Recently, Budi-Santoso and Lesage (2016) applied these two techniques simultaneously. They detected seismic velocity decrease of up to $1.5 \%$ associated with the 2010 eruption at Merapi volcano, Indonesia. Temporal changes in seismic velocity estimated from seismic interferometry analysis displayed non-synchronized changes with those from coda-wave interferometry analysis. Such non-synchronized changes may be caused by the difference of wave fields because the coda-wave interferometry used volcano-tectonic earthquakes occurring at depths of about $0.5-2.3 \mathrm{~km}$ and not at the ground surface. In addition, the errors on vertical locations of volcano-tectonic earthquakes were as large as about a few hundred meters. Cross-correlation coefficients of the similar seismograms were higher than 0.75 . However, that threshold is a little bit lower.
Sakurajima is one of the most active volcanoes in Japan, which is located at the southern rim of Aira caldera in southern Kyushu, Japan. The volcano is well known to exhibit vulcanian eruptions in these decades, and the number of explosions mainly from Showa crater reached 835 in 2012, 883 in 2013, and 450 in 2014 (Japan Meteorological Agency 2015). The volcanic activities have been monitored by various observations: seismic and geodetic measurements as well as volcanic gas observations (e.g., Iguchi et al. 2013). Tsutsui et al. (2016) further repeated active seismic experiments once a year from 2008 and detected temporal changes in reflection coefficients that are inferred to be caused by density or seismic velocity changes in the sill at a depth of around $4.9 \mathrm{~km}$ beneath Sakurajima volcano. However, there is no study so far that applies coda-wave interferometry to the data of the repeated active seismic experiments at Sakurajima. There are only a few researches that continuously monitor temporal structure changes at Sakurajima; Maeda et al. (2015) reported temporal changes in the subsurface structure using waveforms of an active source called accurately controlled routinely operated signal system (ACROSS) during an active eruptive period from September 2012 to July 2014.

In this study, we apply coda-wave interferometry to the repeated active seismic experiments conducted at Sakurajima once a year from 2011 to 2014. Also, we apply seismic interferometry to ambient seismic noise at Sakurajima. Since active seismic sources are located near the ground surface, the seismic waves we analyze in these two kinds of methods are almost same and sample same regions. Most of shot points at each shot site are located within $10 \mathrm{~m}$, and we choose records of which the crosscorrelation coefficient is higher than 0.9 between the two shots. We compare seismic velocity changes obtained from these two methods and discuss a relation between the seismic velocity changes and the volcanic activity at Sakurajima.

\section{Methods \\ Data processing}

We use seismograms recorded at six stations at Sakurajima maintained by Japan Meteorological Agency (JMA). Three-component short-period seismometers with a natural frequency of $1 \mathrm{~Hz}$ are installed on the ground surface at three stations of V.SKRB, V.SKRC, and V.SKRD and are installed in boreholes with depths of between 80 and $100 \mathrm{~m}$ at the other three stations of V.SKA2, V.SKD2, and V.SFT2. All the seismograms are recorded with a sampling frequency of $100 \mathrm{~Hz}$ and an A/D resolution of 24 bit. Figure 1 shows the spatial distribution of the JMA seismic stations (squares) and the shot points (stars). 


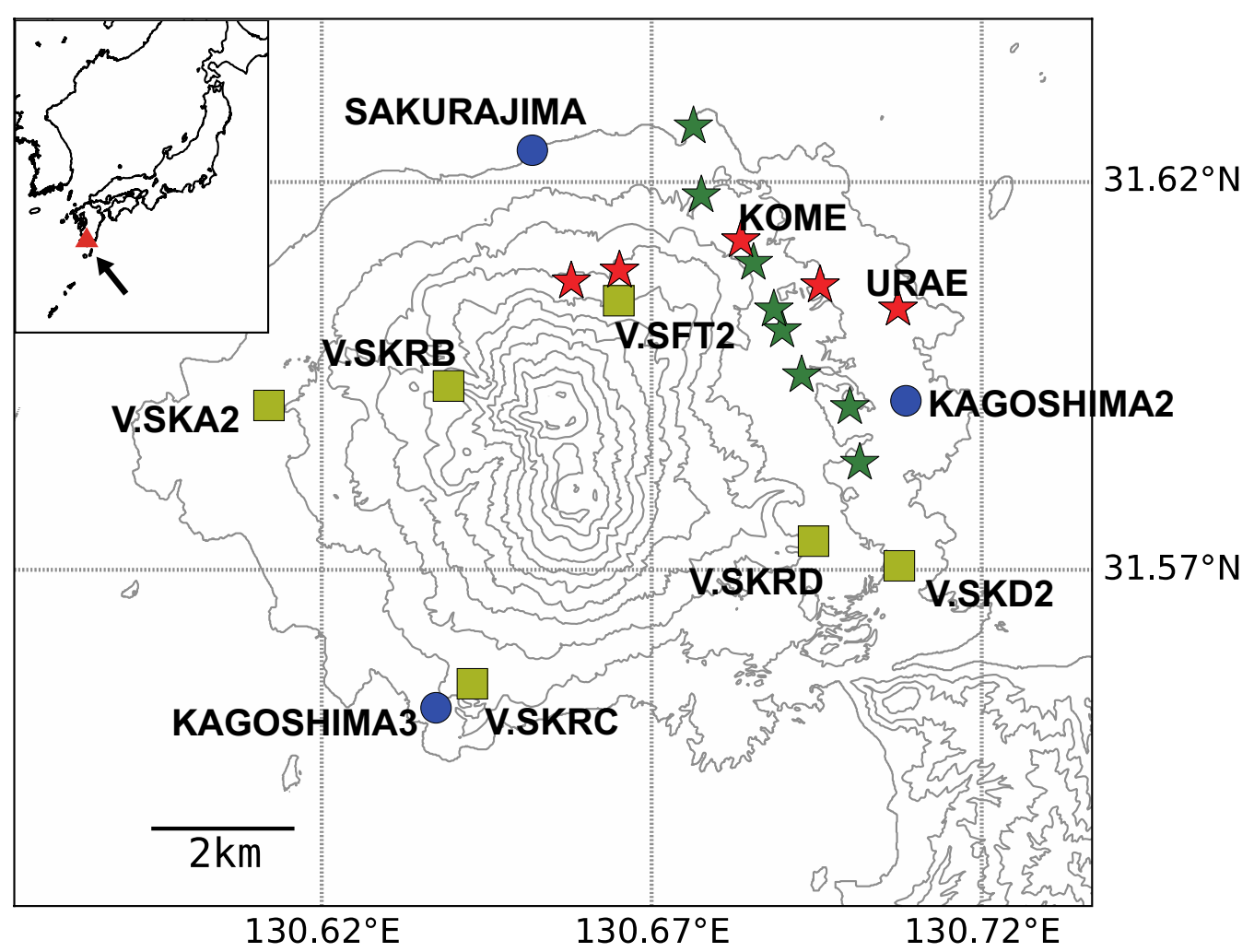

Fig. 1 Spatial distribution of seismometers (squares), GNSS stations (circles), and shot points (stars) at Sakurajima volcano located in Kyushu island, Southwestern Japan (red triangle in the upper left panel). Gray contour lines show the topography of Sakurajima. Thirteen shots are shown by stars and five shots in 2013 are especially shown by red stars

We use the seismic waves excited by repeated active seismic experiments conducted from 2011 to 2014 for analyses of coda-wave interferometry. At each experiment, 5-13 shots using dynamite were conducted on the eastern-northern flank: 13 shots in 2011, 2012 and 2014, while 5 shots in 2013 (shown with red stars in Fig. 1). Dynamite charge of each shot is $20 \mathrm{~kg}$ with an exception at a shot site URAE in 2013 of $200 \mathrm{~kg}$. The shots were detonated inside $10-\mathrm{m}$ deep boreholes. Figure 2 shows an example of the vertical-component velocity seismograms in $4-8 \mathrm{~Hz}$ band at station V.SFT2 for the shots at KOME in 2011 and 2012. The seismograms in 2011 and 2012 are similar to each other as cross-correlation coefficient is 0.925. Since dominant frequencies of the observed seismograms range between 3 and $8 \mathrm{~Hz}$ (Fig. 2), we analyze seismograms filtered in $1-2,2-4,4-8,8-16$, and $16-32 \mathrm{~Hz}$ bands. To obtain accurate velocity changes, we choose records of which the cross-correlation coefficient is higher than 0.9 between the two shots in a time window between 0 and $5 \mathrm{~s}$ in lapse time. We further use signal-to-noise $(\mathrm{S} / \mathrm{N})$ ratio to select the records. Calculating $\mathrm{S} / \mathrm{N}$ ratio from the root-mean-squared (RMS) amplitude of the signal from 0 to $20 \mathrm{~s}$ to that of the noise from -5 to
$0 \mathrm{~s}$, we use the records with $\mathrm{S} / \mathrm{N}$ ratios of larger than 3 for 2011, 2012, and 2014 data. Because of low signal-to-noise ratio, we lower the minimum $\mathrm{S} / \mathrm{N}$ ratio to be 2 only for 2013 data.

Seismic interferometry is applied to the ambient seismic noise data between 2012 and 2014. Ambient noises are first filtered in $1-2,2-4$, and $4-8 \mathrm{~Hz}$ bands. For each frequency band, we choose 10-min-long data having amplitude of smaller than 10 times of the average RMS amplitude of ambient noise recorded in 2012. We apply 1-bit normalization and spectral whitening to reduce the effect of earthquake signals (e.g., Bensen et al. 2007). Finally, cross-correlation functions (CCFs) are calculated every $10 \mathrm{~min}$, and daily CCFs (hereafter called DCCFs) are obtained by stacking the 10-min CCFs every day for 15 pairs from six stations. The obtained DCCFs are considered to be Green's functions recorded at one of a station pair from a virtual source at the other station of the pair.

\section{Estimation method of seismic velocity changes}

To estimate seismic velocity changes, we use Moving Window Cross-Spectral (MWCS) technique (Poupinet 

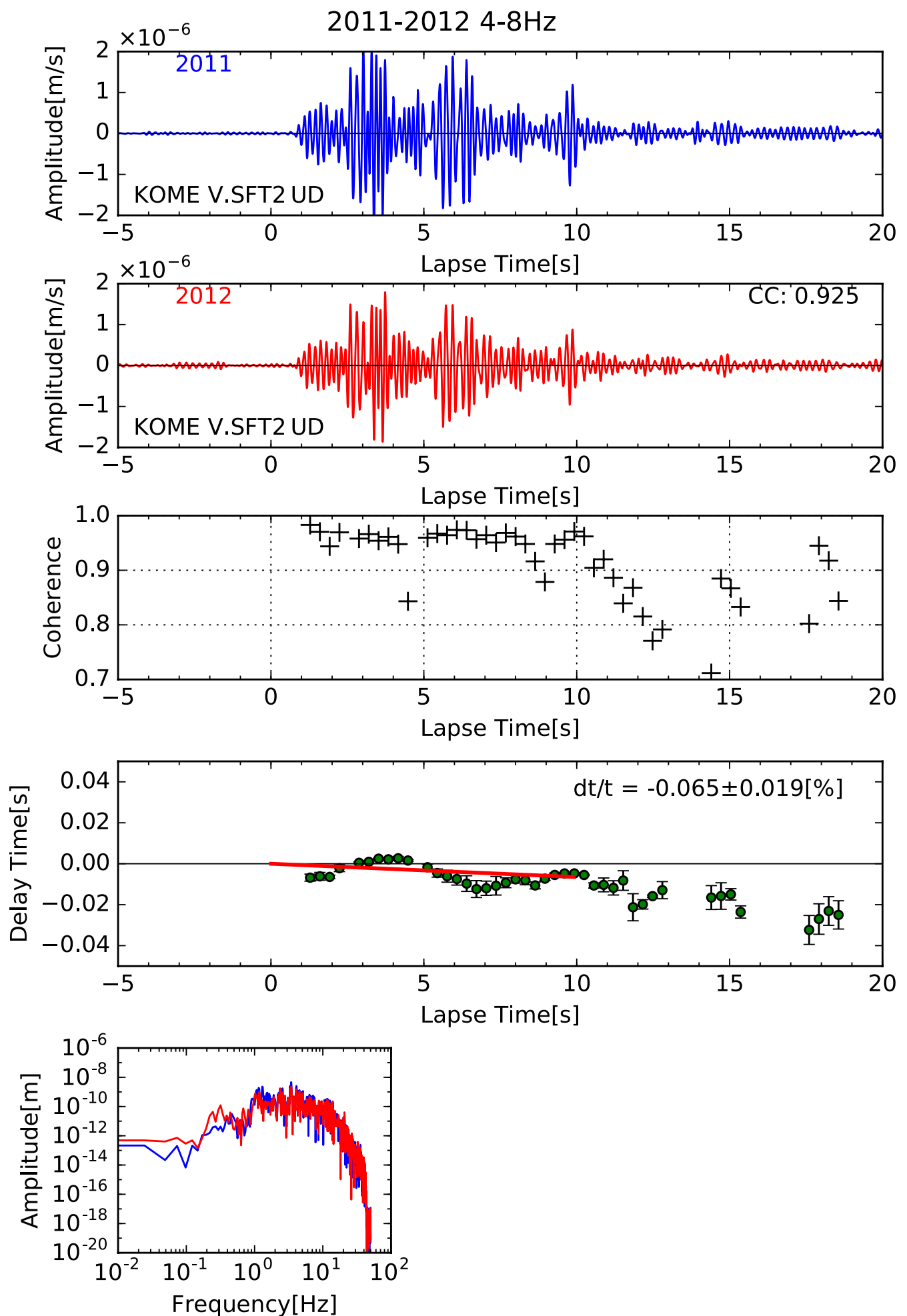

Fig. 2 Velocity seismograms in the $4-8 \mathrm{~Hz}$ and observed velocity spectra at station V.SFT2. Top two panels are velocity seismograms for the shots in 2011 and 2012 at KOME. The cross-correlation coefficient is 0.925 in a time window of 0 and $20 \mathrm{~s}$ in lapse time. The third panel from the top is coherence in the short time windows. The fourth panel from the top is an example of estimating $d t / t$ using MWCS technique and the linear regression. The bottom panel shows observed velocity Fourier spectra 
et al. 1984). In this method, delay times, $d t$, between two similar seismograms are calculated at respective lapse times using a relation, $\phi(f)=2 \pi f d t$, where $\phi$ is the phase of cross-spectrum and $f$ is the frequency, for consecutively overlapping short time windows. We set the length of the short time windows to be $2.56 \mathrm{~s}$ for $1-2$ and $2-4 \mathrm{~Hz}, 1.28 \mathrm{~s}$ for $4-8 \mathrm{~Hz}, 0.64 \mathrm{~s}$ for $8-16 \mathrm{~Hz}$, and $0.32 \mathrm{~s}$ for $16-32 \mathrm{~Hz}$, respectively, which are overlapped by $75 \%$ with the adjacent time windows. Assuming a spatially homogeneous velocity change, we derive a relation of $d t / t=-d v / v$, where $v$ is the seismic velocity, and $t$ is the lapse time. We estimate relative velocity changes $d v / v$ from linear regression of the delay time with respect to the lapse time for the data whose cross-correlation coefficients are higher than 0.7 in the short time windows. Coherences in the short time windows and an example of estimating $d t / t$ are shown in Fig. 2. Coherences become lower from around $10 \mathrm{~s}$ in lapse times. From this reason, records of the repeated active seismic experiments in lapse times between $0 \mathrm{~s}$ and $10 \mathrm{~s}$ are used in coda-wave interferometry analysis. In seismic interferometry analysis, DCCFs in lag times between -10 and +10 s are used. Each DCCF is cross-correlated with a reference CCF, which is calculated by stacking DCCFs over 2012 and 2013.

\section{Results}

\section{Coda-wave interferometry}

We calculate relative velocity changes for all combinations of the shot year. The number of shots in 2013 is fewer than the other years. Hence, we consider the velocity changes of 2011, 2013, 2014 with respect to that of 2012 as our representative results. Relative velocity changes are obtained for about 5-15 paths between the shot and stations for each pair of the shots (Table 1). Totally, 280 paths, which is about $10 \%$ of all the combinations for all pairs of the shots, are measured. This may be because active shots using dynamite charge of $20 \mathrm{~kg}$ were so small that only stations on the northeastern flank of the volcano recorded seismic waves with good $\mathrm{S} / \mathrm{N}$ ratios. For the $1-2$ and $16-32 \mathrm{~Hz}$ band, the $\mathrm{S} / \mathrm{N}$ ratio or cross-correlation coefficient is too low to estimate relative velocity changes. The spatial distribution of the estimated relative velocity changes is shown in Fig. 3. Seismic velocity changes are shown by colors of lines connecting the stations and the shot points. Blue lines show velocity increases and red ones show velocity decreases. Seismic velocity increase is dominant both for the periods of 2011-2012 and 2012-2013. Both seismic velocity increase and decrease are found for the period of 2012-2014. Most of the paths for which significant seismic velocity changes are detected are located in the northern-eastern flank of the volcano. Absolute values of
Table 1 Mean values of relative velocity changes from the coda-wave interferometry analysis of the vertical-component records

\begin{tabular}{llll}
\hline $\begin{array}{l}\text { Period } \\
\text { of time }\end{array}$ & $\mathbf{2 - 4 ~ H z}$ & $\mathbf{4 - 8 ~ H z}$ & $\mathbf{8 - 1 6 ~ H z}$ \\
\hline $2011-2012$ & $+0.016 \pm 0.089 \%(7)$ & $+0.038 \pm 0.059 \%(20)$ & $+0.044 \pm 0.042 \%(17)$ \\
$2012-2013$ & $+0.130 \pm 0.137 \%(4)$ & $+0.049 \pm 0.054 \%(4)$ & $+0.046 \pm 0.034 \%(2)$ \\
$2013-2014$ & $-0.064 \pm 0.089 \%(4)$ & $-0.030 \pm 0.100 \%(7)$ & $-0.012 \pm 0.089 \%(4)$ \\
$2011-2013$ & $+0.225 \pm 0.152 \%(4)$ & $+0.144 \pm 0.096 \%(3)$ & No data \\
$2011-2014$ & $+0.002 \pm 0.121 \%(13)$ & $-0.004 \pm 0.049 \%(15)$ & $+0.018 \pm 0.055 \%(8)$ \\
$2012-2014$ & $-0.008 \pm 0.115 \%(9)$ & $+0.027 \pm 0.052 \%(12)$ & $+0.015 \pm 0.048 \%(15)$
\end{tabular}

Numbers in bracket represent the number of paths

the relative velocity changes show a frequency dependence; seismic velocity changes become smaller at higher frequencies, and vice versa: at a maximum $0.47 \pm 0.06 \%$ for $2-4 \mathrm{~Hz}, 0.24 \pm 0.03 \%$ for $4-8 \mathrm{~Hz}$, and $0.15 \pm 0.03 \%$ for $8-16 \mathrm{~Hz}$, respectively. The errors of the estimations are approximately $0.01-0.03 \%$ on average. Though some paths show opposite polarity in values of the relative velocity change, the errors in those paths are not so large compared to other paths. We also show the results for all combinations of the shot year in Table 1 . Seismic velocity decrease is found only for the period of 2013-2014.

We only use records of which the cross-correlation coefficient is higher than 0.9 . Hence, the obtained results are reliable. However, the dynamite charge of $20 \mathrm{~kg}$ for all the shots except one at Sakurajima restricts the estimation of the velocity changes to the northeastern flank of the volcano. This limitation of wave paths makes it difficult to compare the results obtained from coda-wave interferometry and those from seismic interferometry for almost identical wave paths (only a few exceptions are shown in Additional file 1). For this reason, we average the values of relative velocity changes for all shot-station pairs when we compare the results from coda-wave interferometry with those from seismic interferometry.

\section{Seismic interferometry}

We estimate relative velocity changes for 15 station pairs (all pairs among six stations) at Sakurajima by calculating DCCFs over the 3 years between 2012 and 2014. We do not estimate relative velocity changes for five pairs in February 2012 and for nine pairs in August 2013 because of low $\mathrm{S} / \mathrm{N}$ ratio of the records. However, we are able to estimate relative velocity changes for the other observation periods and discuss temporal changes in seismic velocity almost all the way from January 1, 2012, to December 31,2014 , by seismic interferometry. Temporal changes in DCCFs for the pair V.SFT2-V.SKD2, separation distance of $5.5 \mathrm{~km}$, are shown as an example in Fig. 4. For this pair, there is a phase with large amplitude around $4 \mathrm{~s}$ in lag 

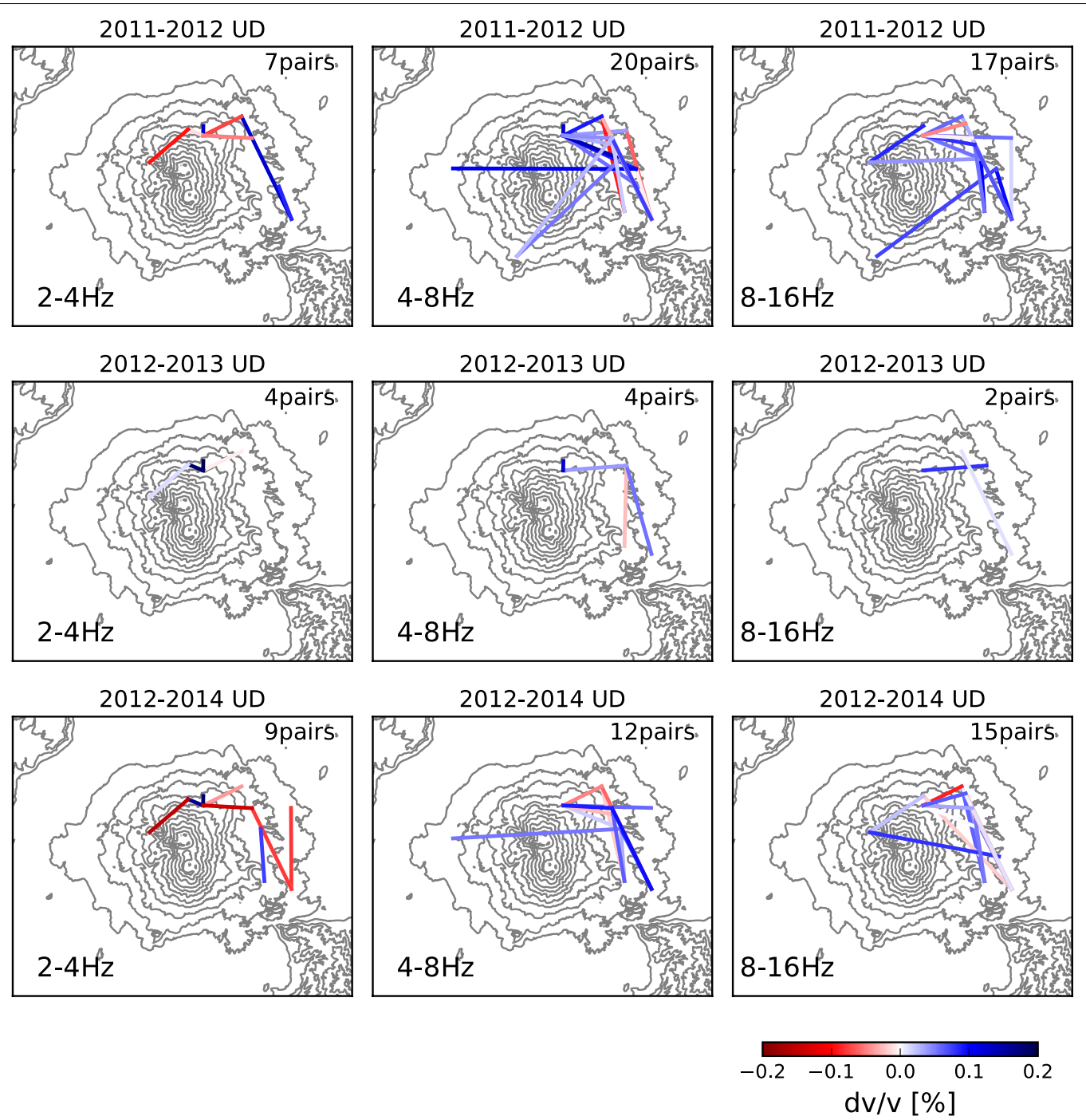

Fig. 3 Spatial distribution of seismic velocity changes estimated from the coda-wave interferometry analysis of the vertical-component records in 2011-2012, 2012-2013, and 2012-2014 periods. The results are shown for 2-4, 4-8, and 8-16 Hz, and lines connect the stations and shot points. Blue lines indicate seismic velocity increase and red ones show decrease

time. Assuming that this phase is direct wave, the propagation velocity of this phase is approximately $1.4 \mathrm{~km} / \mathrm{s}$. Miyamachi et al. (2013) estimated the P-wave velocity of about $2.3-2.8 \mathrm{~km} / \mathrm{s}$ in the area shallower than $1 \mathrm{~km}$ at Sakurajima. From this result, the phase around $4 \mathrm{~s}$ in lag time is thought of as S-wave or Rayleigh wave. A reference CCF is exhibited by a black solid curve on the top of the figure, and an example of estimating $d t / t$ is shown on the bottom. Temporal changes in seismic velocity estimated from the CCFs are shown in Fig. 5. For this station pair, an almost annual oscillation is found for all the frequency bands. For example, the relative velocity changes are negative until August 2012, turn to positive, and keep it until February 2013 and turn into negative again. Similar periodical oscillations are recognized during 3 years for most of the station pairs and all frequency bands. Amplitudes of these periodical oscillations are at a maximum $2 \%$ for $1-2 \mathrm{~Hz}, 1 \%$ for $2-4 \mathrm{~Hz}$, and $0.5 \%$ for $4-8 \mathrm{~Hz}$, respectively, indicating a frequency dependence of velocity changes.

Lastly, we average the data of the relative velocity changes for seismic interferometry from all 15 station pairs. Daily variations of the values of relative velocity changes obtained from seismic interferometry analysis are large for each station pair (each path). Therefore, it is difficult to directly compare the values of relative velocity changes from coda-wave interferometry with those on shot days from seismic interferometry with high accuracy for a limited number of almost identical paths (see Additional file 1 for a few exceptions). Furthermore, 


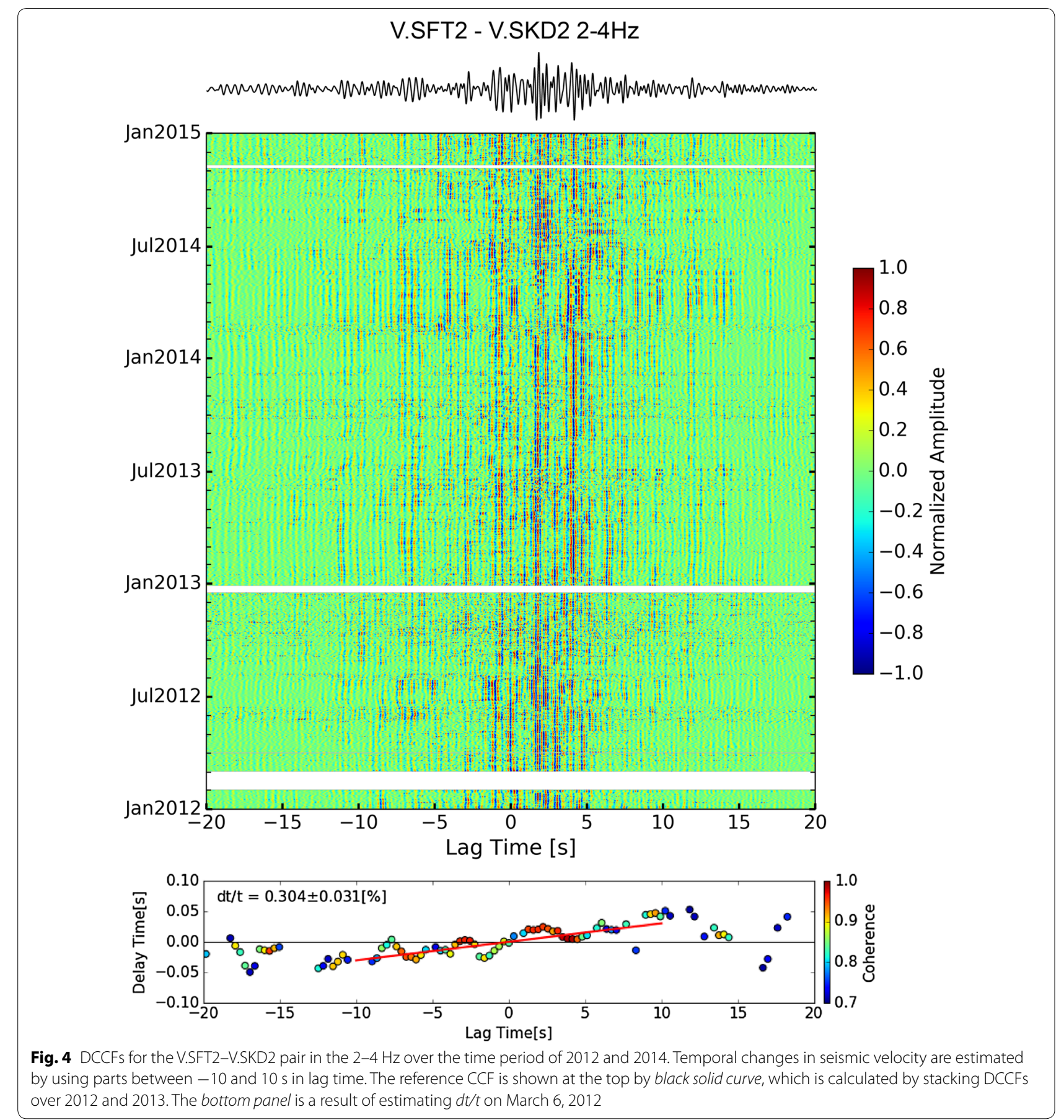

we can reduce the effect of the seasonal variation of noise sources by averaging for all 15 station pairs having different configurations (e.g., Froment et al. 2010). Those values are shown in Fig. 6 by gray dots. Error bars show \pm one standard deviation with respect to the different station pairs. Amplitude of velocity change is $\pm 0.3 \%$ for $1-2 \mathrm{~Hz}, \pm 0.4 \%$ for $2-4 \mathrm{~Hz}$, and $\pm 0.2 \%$ for $4-8 \mathrm{~Hz}$, respectively. The almost annual change is clearly seen by averaging the seismic velocity change, especially for $2-4$ and $4-8 \mathrm{~Hz}$ band. We discuss the mechanism of this periodic seismic velocity oscillation in the next section.

\section{Discussion}

We compare the results obtained from coda-wave interferometry with those from seismic interferometry. Mean 

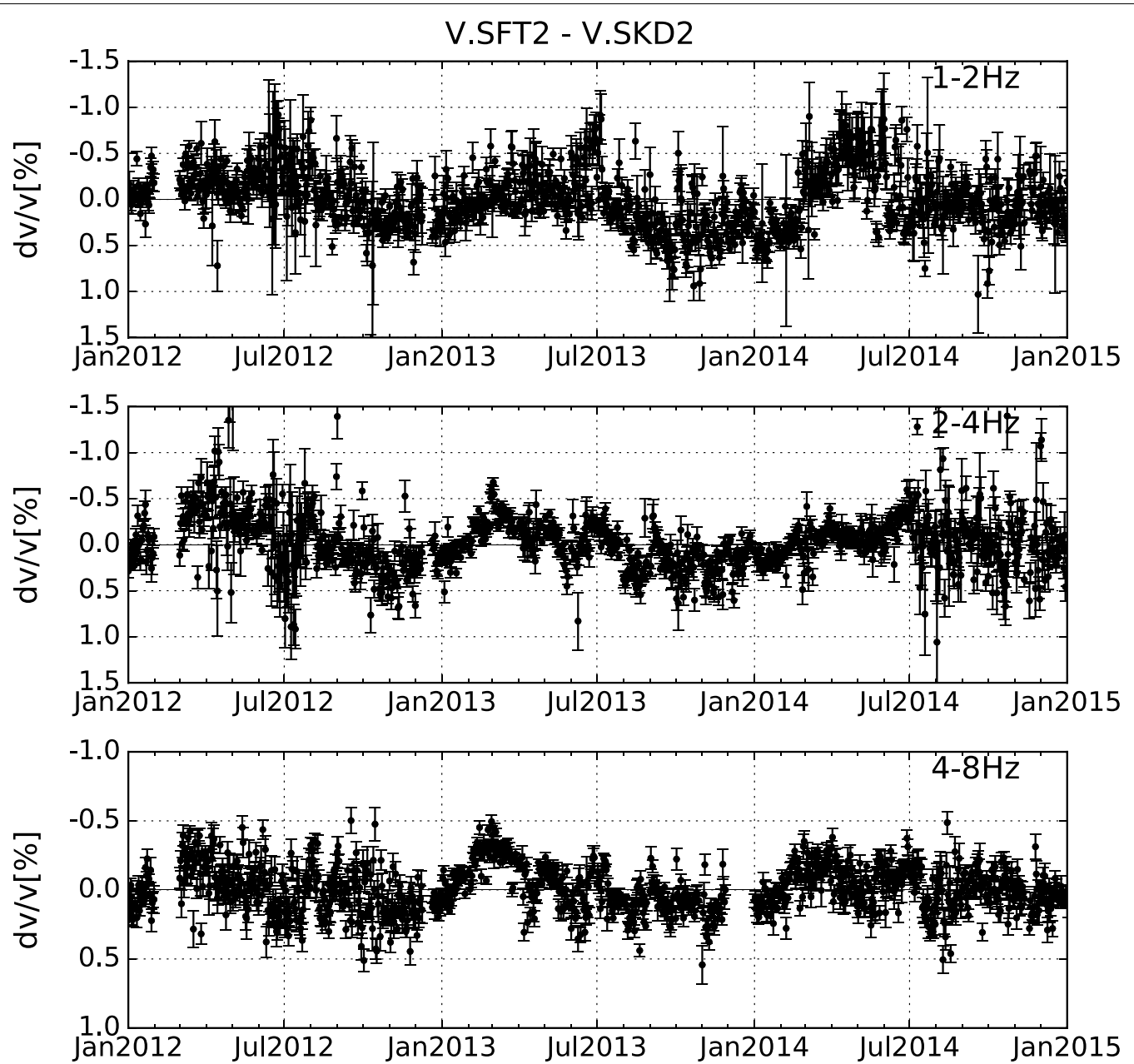

Fig. 5 Temporal changes in relative seismic velocity for the V.SFT2-V.SKD2 pair. The results for 1-2, 2-4, and 4-8 $\mathrm{Hz}$ are shown from the top to the bottom. Black dots are the relative seismic velocity changes estimated day by day, and vertical bars show their SD

values of the relative velocity changes from coda-wave interferometry are calculated by averaging the results from the vertical component for all shot-station pairs. Results of seismic interferometry are also averaged for all 15 station pairs. In Fig. 6, the mean relative velocity changes shown by red squares are overwritten by assuming that the results for the 2012 experiment are the same as those on the same day from seismic interferometry. Error bars show \pm one standard deviation. The mean relative velocity changes distribute within the variability among station pairs in seismic interferometry between 2012 and 2014 in $2-4$ and $4-8 \mathrm{~Hz}$ band. Hence, the results from these two techniques are consistent with each other. This is also supported by comparing the results of coda-wave interferometry and those of seismic interferometry for only a few almost identical paths (Additional file 1).
We compared the velocity changes of 2011, 2013, 2014 to that of 2012 at first. However, other choices of a reference year and combination of two shot years are possible. Since there is no result from seismic interferometry in 2011, we cannot use 2011 as the reference year due to the unavailability of data. In Fig. 6a, we show the differences by changing the reference year. Pairs of shot years are fixed to be 2011-2012, 2012-2013, and 2012-2014. Different colors indicate the differences of the reference year (2012: red, 2013: blue, 2014: green). Blue line slightly shifts to the above from the other two. However, the values of mean relative velocity changes are still within pair variations in seismic interferometry between 2012 and 2014. The results of all three patterns are almost the same in $4-8 \mathrm{~Hz}$ band. In Fig. 6b, we show the results of various combinations of two shot years. Calculated mean relative velocity changes from 2013 to 2014 are shown by green, 

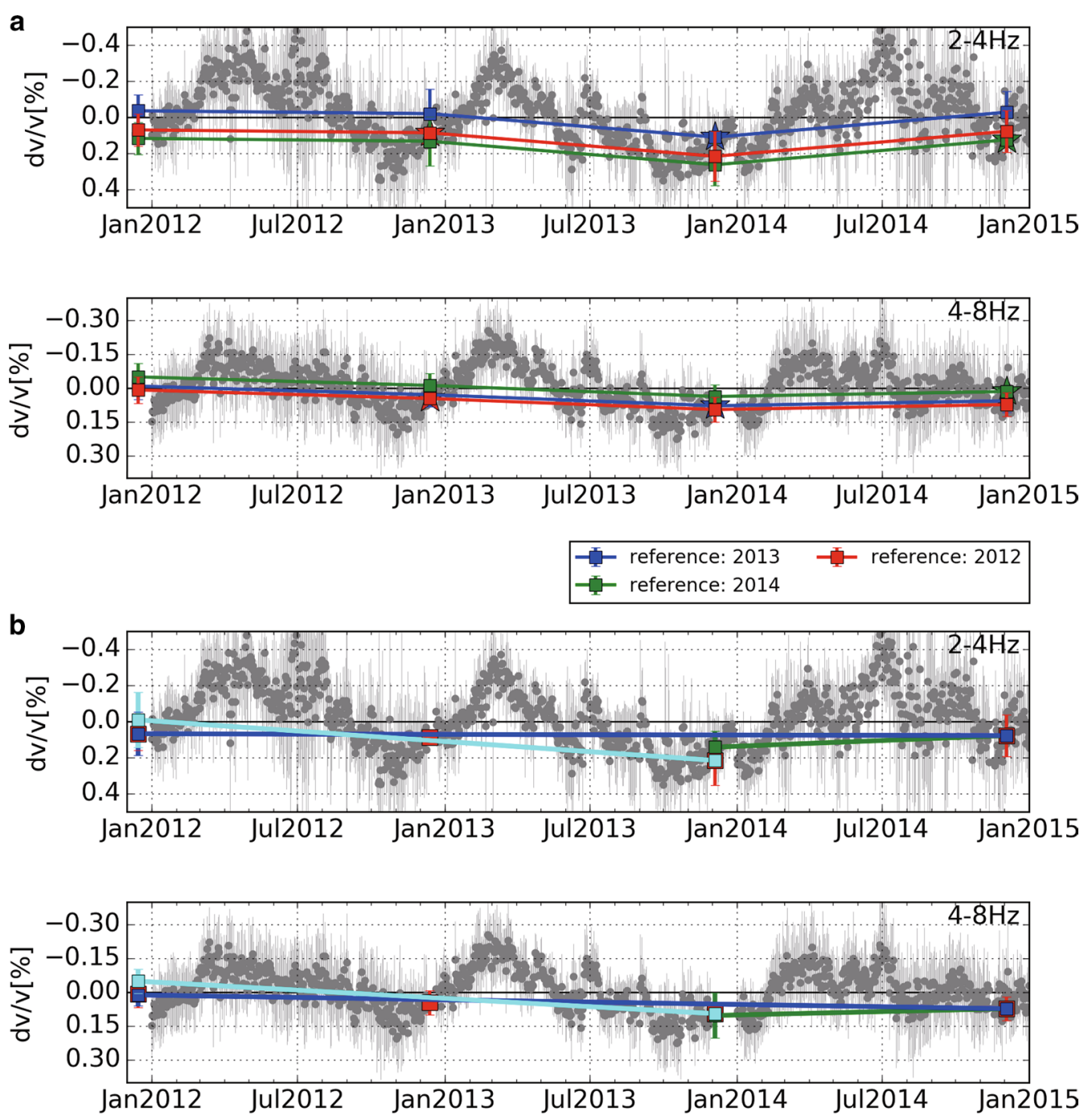

$\begin{array}{ll}2011-2012,2012-2013,2012-2014 & -1-2011-2014 \\ 2013-2014 & \square-2011-2013\end{array}$

Fig. 6 Comparison between the results of the coda-wave interferometry analysis with those of the seismic interferometry analysis. The results from the seismic interferometry analysis (gray dots) are calculated by stacking the results for all station pairs. Error bars show \pm one standard deviations. Those from the coda-wave interferometry analysis are mean values of relative velocity changes for the vertical component. The mean relative velocity changes calculated every other year (2011-2012, 2012-2013,2012-2014) are shown by red square symbols. a Results for the different reference years (blue 2013 and green 2014). Stars indicate the reference year. b Results for the shots between 2013 and 2014 (green), 2011 and 2014 (blue), and 2011 and 2013 (cyan)

those from 2011 to 2014 by blue, and those from 2011 to 2013 by cyan. Plots by red indicate the velocity changes in each year to that of 2012. The differences between them are quite small both in $2-4$ and in $4-8 \mathrm{~Hz}$ bands, at a maximum about $0.05 \%$ in $2-4 \mathrm{~Hz}$ band for the case of 2011-2013. Those comparisons indicate that we can obtain reliable results from coda-wave interferometry.

We have compared the mean values of velocity changes. To see the spatial variations of velocity changes, we need to consider sensitivity kernels (e.g., Pacheco and Snieder 2005). The kernels have two peaks at the position of the source and station (see Additional file 2). Therefore, measured velocity changes are expected to be sensitive to local changes at the source and station. Coda waves that we use are probably the mixture of body waves and surface waves. One advantage of our study is that both of shot points and stations are located at near surface. Therefore, the sensitivity kernels have large sensitivities 

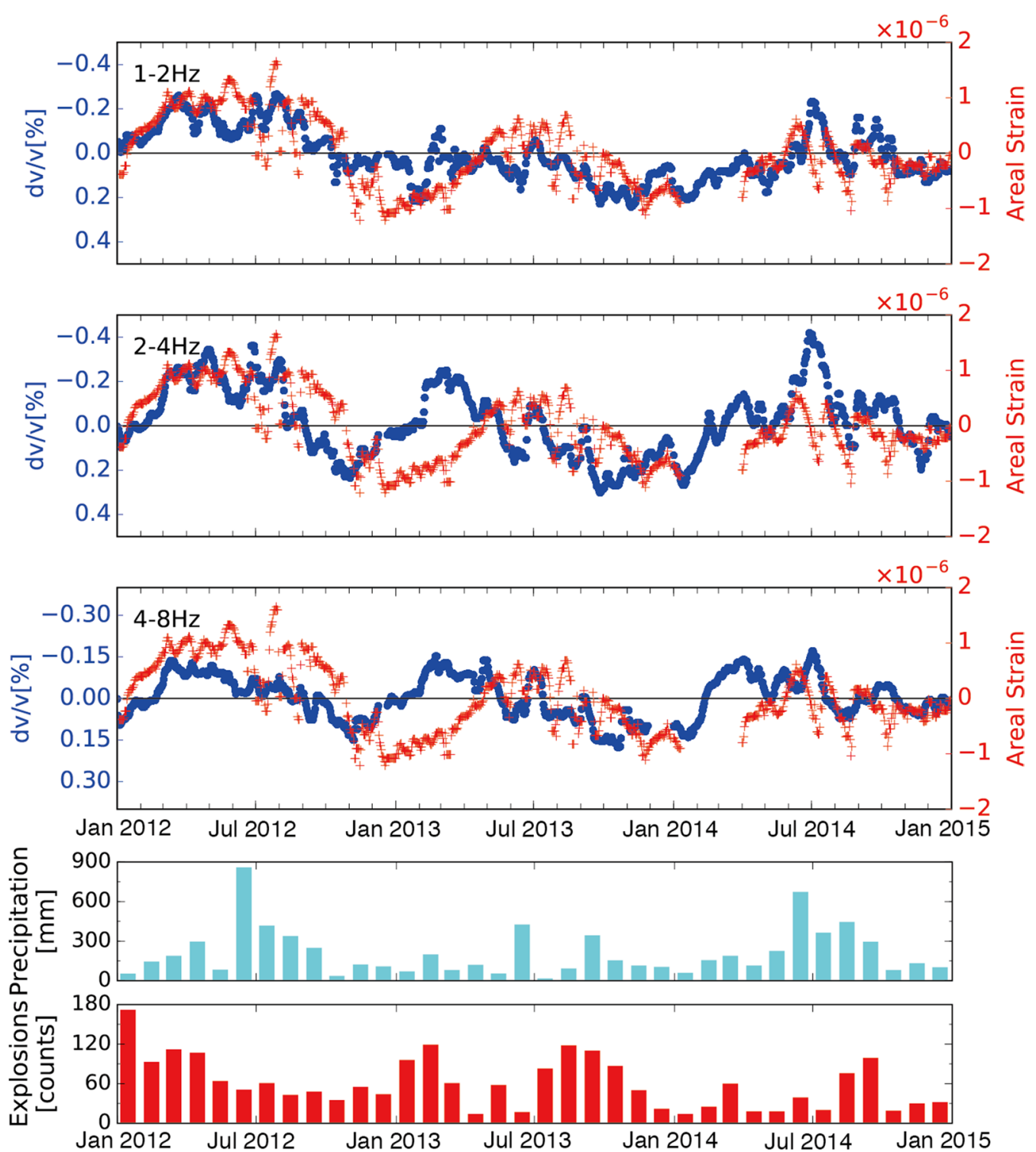

Fig. 7 Comparison of temporal changes in seismic velocity with those of areal strains calculated from GNSS data. Red plus symbols indicate the areal strain of a triangle composed of three GNSS stations of Sakurajima, Kagoshima2, and Kagoshima3. Blue dots indicate the relative velocity changes estimated by seismic interferometry. The results from the seismic interferometry analysis are stacked values for all station pairs. A median filter with a time window length of 10 days is applied to the both data. Two bar plots indicate monthly precipitation (cyan) and the number of explosions per month (red), respectively

near the surface regardless of the predominance of either body waves or surface waves. Almost annual changes in seismic velocity are detected commonly for many shot-station pairs and station pairs. This suggests that the almost annual changes in seismic velocity take place at shallow depths widely over Sakurajima. On the other hand, it is true that the spatial variation of the estimated relative velocity change exists, especially in the shorterperiod component. So far, causes of such spatial variation are not clear yet, though it may reflect structural changes in the vicinity of shot points or stations.
To interpret physical mechanism of temporal changes in seismic velocity, we compare them with geodetic data. Global navigation satellite system (GNSS) receivers, extensometers, and tilt meters are installed at Sakurajima to monitor the deformation of the volcano edifice (e.g., Japan Meteorological Agency 2015). In the present study, we use three GNSS stations of Geospatial Information Authority of Japan (GSI) at Sakurajima (the locations are shown by circles in Fig. 1). Using the daily coordinates of the three stations (Sakurajima, Kagoshima2, and Kagoshima3), we calculate areal strains. In the 
calculation, we remove offsets in the daily coordinates due to the replacement of GNSS antennas at Kagoshima2 and Kagoshima3 on October 26, 2012, by using the difference between the median values calculated from 10 days before and 10 days after the day of the antenna change. The areal strain of zero amplitude is set to be the average value during the 3 years between 2012 and 2014. The areal strains thus calculated are shown by red plus symbols in Fig. 7 . The relative velocity changes from seismic interferometry are shown by blue dots. Note that we apply a median filter with a time window length of 10 days to both of the data to remove outliers. Changes in the areal strain are well correlated with those in seismic wave velocity in terms of not only the almost annual change but also much shorterperiod components down to about 1 month. The correlation is better at $1-2 \mathrm{~Hz}$ throughout 3 years. At $2-4$ and $4-8 \mathrm{~Hz}$, the correlation is also better except a period from December 2012 to April 2013. Precipitation shows seasonal variations at Sakurajima: high in summer and low in winter. However, there seems no clear seismic velocity decrease related to high precipitation. Moreover, there seems no significant correlation between seismic velocity changes and the number of explosions as well; the number of explosions is a bit large from January 2013 to February 2013 and from July 2013 to October 2013, but no associated changes in seismic velocity are found in these periods. Moreover, we consider thermoelastic effects (e.g., Tsai 2011). However, we find that the expected seismic velocity changes due to the thermoelastic effects are almost in antiphase with the observed seismic velocity changes. Therefore, it is not clear why correlation between seismic velocity changes and areal strains is not good from December 2012 to April 2013.

We estimate strain sensitivities of seismic velocity changes using the areal strain values to be about $2.0 \times 10^{3} /$ strain at $1-2 \mathrm{~Hz}$. This sensitivity ranges within previously reported values that are compiled in Nishimura et al. (2005). Such consistency strongly suggests that observed annual changes in seismic velocity are related to strain changes in volcanic edifice. At Sakurajima, spherical pressure sources that explain observed ground deformation between November 2009 and April 2010 well are estimated at a depth of about $12 \mathrm{~km}$ beneath the Aira caldera (north of Sakurajima) and at a depth of about $5 \mathrm{~km}$ beneath Kita-dake (north part of Sakurajima) (e.g., Iguchi et al. 2013). However, there is no study which explains geodetic data in other periods of time as far as we know. Therefore, the reason why geodetic data show the annual-like change is not clear yet.

\section{Conclusions}

We examined seismic velocity changes at Sakurajima from 2011 to 2014 by combining coda-wave interferometry analysis of the repeated active seismic experiments and seismic interferometry analysis of ambient seismic noise. The sources of active seismic experiments are located near the ground surface, which enabled us to directly compare seismic velocity changes from these two techniques. We compare the results obtained from two techniques for all reference years and combinations of two shot years. In all cases, the results from these two techniques are consistent with each other. The values of mean relative velocity changes in coda-wave interferometry are within the variability among station pairs in seismic interferometry between 2012 and 2014 in 2-4 and 4-8 Hz band. Almost annual change in relative velocity changes is clearly found in both of the estimated seismic velocity changes and geodetic signals from GNSS receivers, which is a clear example that seismic velocity is well correlated with geodetic signals at a volcano. The combined use of coda-wave interferometry and seismic interferometry is shown to be effective to obtain reliable and continuous measurements of seismic velocity changes. This technique will be useful as one of monitoring tools of volcanoes.

\section{Additional files}

Additional file 1. Comparison of the results of coda-wave interferometry and seismic interferometry on the almost identical wave paths. Gray dots in top two panels are daily $\mathrm{dv} / \mathrm{v}$ values obtained from seismic interferometry. The $d v / v$ values obtained from coda-wave interferometry are shown by red squares and are overwritten assuming that the results for the 2012 experiment are the same as those on the same day from seismic interferometry. Error bars show \pm one standard deviation. Spatial distribution of three seismometers (squares) and a shot point (star) used in top two panels is shown in the bottom pane/ with black letters and red letters, respectively.

Additional file 2. Examples of sensitivity kernels in 2D and 3D at a lapse time of $10 \mathrm{~s}$. Upper left panel shows a sensitivity kernel in 2D based on diffusion model. A yellow star and a red triangle indicate source and receiver, respectively. Upper right panel is a projected plot of the sensitivity kernel in upper left panel. A sensitivity kernel in 3D based on diffusion model and its projected plot are shown in lower left panel and lower right panel, respectively.

\section{Authors' contributions}

TH (corresponding author) carried out the analyses and drafted the manuscript. All authors read and approved the final manuscript.

\section{Acknowledgements}

We used seismograms obtained from active seismic experiments conducted by Disaster Prevention Research Institute, Kyoto University, other eight Japanese universities, and Japan Meteorological Agency (JMA) at Sakurajima. Especially, we are very grateful to Profs. Tomoki Tsutsui and Masato Iguchi for their leadership to conduct the active seismic experiments for as long as 6 years from 2008 to 2014. Our coda-wave interferometry analysis would not be possible without their great efforts. We are also grateful to JMA for providing us with continuous seismic data recorded at 6 stations. We thank Geospatial Information Authority of Japan for making available GNSS data and Digital Elevation Model data with a mesh size of $10 \mathrm{~m}$. We appreciate many constructive comments from an associate editor, Prof. Hiroshi Takenaka, and two anonymous reviewers. This study was supported by Ministry of Education, Culture, Sports, Science and Technology (MEXT) of Japan, under its Earthquake and Volcano Hazards Observation and Research Program. 


\section{Competing interests}

The authors declare that they have no competing interests.

Received: 4 September 2016 Accepted: 31 January 2017 Published online: 13 March 2017

\section{References}

Bensen GD, Ritzwoller MH, Barmin MP, Levshin AL, Lin F, Moschetti MP, Shapiro NM, Yang Y (2007) Processing seismic ambient noise data to obtain reliable broad-band surface wave dispersion measurements. Geophys J Int 169:1239-1260

Brenguier F, Shapiro NM, Campillo M, Ferrazzini V, Duputel Z, Coutant O, Nercessian A (2008) Towards forecasting volcanic eruptions using seismic noise. Nat Geosci 1:126-130

Budi-Santoso A, Lesage P (2016) Velocity variations associated with the large 2010 eruption of Merapi volcano, Java, retrieved from seismic multiplets and ambient noise cross-correlation. Geophys J Int 206:221-240

Cannata A (2012) Crustal changes at Mt. Etna volcano accompanying to 2002-2003 eruption as inferred from a repeating earthquake analysis. Geophys Res Lett 39:L18311. doi:10.1029/2012GL0531853

Curtis A, Gerstoft P, Sato H, Snieder R, Wapenaar K (2006) Seismic interferometry—turning noise into signal. Lead Edge 25:1082-1092. doi:10.1016/j. jvolgeores.2006.04.003

Froment B, Campillo M, Roux P, Gouedard P, Verdel A, Weaver RL (2010) Estimation of the effect of nonisotropically distributed energy on the apparent arrival time in correlations. Geophysics 75:SA85-SA93. doi:10.1190/1.3483102

Iguchi M, Tameguri T, Ohta Y, Ueki S, Nakao S (2013) Characteristics of volcanic activity at Sakurajima volcano's Showa crater during the period 2006 to 2011. Bull Volcanol Soc Jpn 58:115-135

Japan Meteorological Agency (2015) (1) Sakurajima. Documents for the 132th meeting of the coordinating committee for prediction of volcanic eruptions (in Japanese). http://www.data.jma.go.jp/svd/vois/data/tokyo/ STOCK/kaisetsu/CCPVE/shiryo/129/132_no02.pdf. Accessed 31 Mar 2016

Maeda Y, Yamaoka K, Miyamachi H, Watanabe T, Kunitomo T, Ikuta R, Yakiwara H, Iguchi M (2015) A subsurface structure change associated with the eruptive activity at Sakurajima Volcano, Japan, inferred from an accurately controlled source. Geophys Res Lett 42:5179-5186

Miyamachi H, Tomari C, Yakiwara H, Iguchi M, Tameguri T, Yamamoto K, Ohkura T, Ando T, Onishi K, Shimizu H, Yamashita Y, Nakamichi H, Yamawaki T, Oikawa J, Ueki S, Koeda T, Masuda Y, Katou K, Hatakeyama K, Kobayashi T (2013) Shallow velocity structure beneath the Aira caldera and Sakurajima Volcano as inferred from refraction analysis of the seismic experiment in 2008. Bull Volcanol Soc Jpn 58:227-237
Nishimura T, Uchida N, Sato H, Ohtake M, Tanaka S, Hamaguchi H (2000) Temporal changes of the crustal structure associated with the M6.1 earthquake on September 3, 1998, and the volcanic activity of Mount Iwate, Japan. Geophys Res Lett 27:269-272

Nishimura T, Tanaka S, Yamawaki T, Yamamoto H, Sano T, Sato M, Nakahara H, Uchida N, Hori S, Sato H (2005) Temporal changes in seismic velocity of the crust around Iwate volcano, Japan, as inferred from analyses of repeated active seismic experiment data from 1998 to 2003. Earth Planets Space 57(6):491-505. doi:10.1186/BF03352583

Pacheco C, Snieder R (2005) Time-lapse travel time change of multiply scattered acoustic waves. J Acoust Soc Am 118(3):1300-1310

Poupinet G, Ellsworth WL, Frechet J (1984) Monitoring velocity variations in the crust using earthquake doublets: an application to the Calaveras Fault, California. J Geophys Res 89:5719-5731

Sens-Schönfelder C, Wegler U (2011) Passive image interferometry for monitoring crustal changes with ambient seismic noise. CR Geosci 343:639-651

Shapiro N, Campillo M (2004) Emergence of broadband Rayleigh waves from correlations of the ambient seismic noise. Geophys Res Lett 31(7):L07614 doi:10.1029/2004gl019491

Snieder R (2006) The theory of coda wave interferometry. Pure appl Geophys 163:455-473

Snieder R, Grêt A, Douma H, Scales I (2002) Coda wave interferometry for estimating nonlinear behavior in seismic velocity. Science 295(5563):2253-2255

Stehly L, Campillo M, Shapiro NM (2006) A study of the seismic noise from its long-range correlation properties. J Geophys Res 111:B10306. doi:10.102 9/2005jb004237

Takagi R, Okada T, Nakahara H, Umino N, Hasegawa A (2012) Coseismic velocity change in and around the focal region of the 2008 IwateMiyagi Nairiku earthquake. J Geophys Res 117:B06315. doi:10.1029/201 2jb009252

Tsai VC (2011) A model for seasonal changes in GPS positions and seismic wave speeds due to thermoelastic and hydrologic variations. J Geophys Res 116:B04404. doi:10.1029/2010JB008156

Tsutsui T, Iguchi M, Nakamichi H, Tameguri T, Nakamichi H (2016) Structural evolution beneath Sakurajima volcano, Japan, revealed through rounds of controlled seismic experiments. J Volcanol Geotherm Res 315:1-14. doi:10.1016/j.jvolgeores.2016.02.008

\section{Submit your manuscript to a SpringerOpen ${ }^{\circ}$ journal and benefit from:}

- Convenient online submission

- Rigorous peer review

- Immediate publication on acceptance

- Open access: articles freely available online

- High visibility within the field

- Retaining the copyright to your article

Submit your next manuscript at $\boldsymbol{\nabla}$ springeropen.com 